\title{
Estratégia\&Negócios
}

ISSN 1984-3372

http://www.portaldeperiodicos.unisul.br/index.php/EeN/

\section{CARACTERÍSTICAS DA MEDIÇÃO DE DESEMPENHO ORGANIZACIONAL: UM ESTUDO DESCRITIVO NOS HOSPITAIS DO ESTADO DO RIO GRANDE DO NORTE}

\section{CHARACTERISTICS OF MEASURING ORGANIZATIONAL PERFORMANCE: A STUDY IN DESCRIPTION IN RIO GRANDE DO NORTE'S HOSPITALS}

\section{Edzana Roberta F. da C. V. Lucena}

Doutorando do Programa Multiinstitucional e Inter-Regional de Pós-graduação em Ciências Contábeis - UnB/ UFPB/ UFRN.

E-mail: edzana@hotmail.com

\section{Aneide Oliveira Araújo}

Professora da UFRN e do Programa Multiinstitucional e Inter-Regional de Pós-graduação em Ciências Contábeis UnB/ UFPB/ UFRN.

E-mail: aneide@ufrnet.br

\section{César Augusto Tibúrcio Silva}

Professor da UnB e do Programa Multiinstitucional e Inter-Regional de Pós-graduação em Ciências Contábeis - UnB/ UFPB/ UFRN.

E-mail: cesartiburcio@unb.br

Recebido em 27/09/2011. Aprovado em 05/11/2011. Disponibilizado em 03/12/2011.

Avaliado pelo Sistema double blind review

R. eletr. estrat. neg., Florianópolis, v.4, n.2, p. 154-180, jun./dez. 2011

http://portaldeperiodicos.unisul.br/index.php/EeN/index
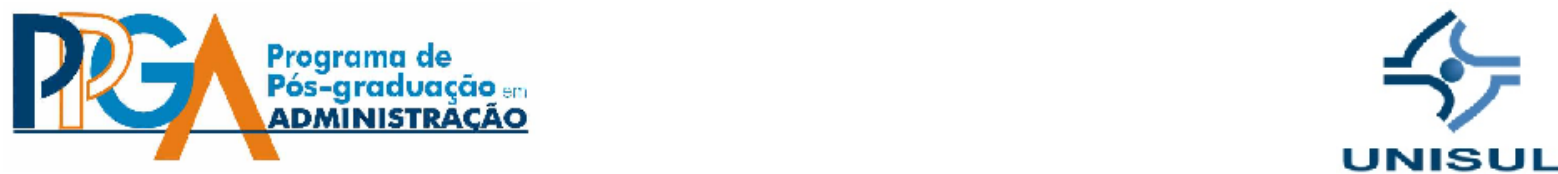

CCopyright 2008 UNISUL-PPGA/Estratégia e Negócios. Todos os direitos reservados. Permitida citação parcial, desde que identificada a fonte. Proibida a reprodução total. Em caso de dúvidas, consulte o editor: ademar.unisul@gmail.com; (48) 3229-1932 


\section{RESUMO}

Essa pesquisa consiste em investigar as principais características da medição de desempenho dos hospitais do Rio Grande do Norte. Para tanto, a metodologia adotada constitui-se de um estudo descritivo, realizado em 46 hospitais do estado, selecionados de forma nãoprobabilística nas cidades de Natal, Mossoró, Parnamirim, São Gonçalo do Amarante, CearáMirim, Macaíba, Caicó, Açu, Currais Novos, São José de Mipibú e Pau dos Ferros. Para a coleta de dados, utiliza-se um formulário objetivo, composto por 32 questões, dispostas em escalas de classificação de categoria simples, múltipla escolha e escala Likert. Após tabulação dos dados realizam-se análise descritiva e testes estatísticos não-paramétricos, Quiquadrado e teste Exato de Fisher. Os resultados demonstram que a maioria das instituições analisadas estão sendo geridas por profissionais com boa qualificação e com conhecimentos em áreas como administração, ciências contábeis, economia e medicina, possuem missão, fazem algum tipo de planejamento, elaboram orçamentos, divulgam seus planos, estratégias e metas, utilizam relatórios e indicadores para a tomada de decisão, avaliam o desempenho e o comparam com organizações de características similares. As hipóteses testadas obtiveram relação significante estatisticamente. Diante desses resultados, pode-se concluir que grande parte dos hospitais constantes na amostra pesquisada, faz uso, em seu processo de gestão, das principais medidas de desempenho investigadas, possuindo dados para avaliar como estão evoluindo no alcance dos objetivos predeterminados e identificar as áreas a serem melhoradas.

Palavras-chave: medição de desempenho. Indicadores financeiros e não financeiros. Instituições Hospitalares.

\section{INTRODUÇÃO}

Os grandes avanços no mundo contemporâneo têm proporcionado às empresas novas oportunidades e desafios no desenvolvimento de suas atividades. Porém, para ganhar R. eletr. estrat. neg., Florianópolis, v.4, n.2, p. 154-180, jun./dez. 2011 
competitividade nesse cenário, as organizações procuram melhorias no desempenho organizacional, mantendo procedimentos de alta qualidade na elaboração de produtos ou na prestação de serviços, a um baixo custo e em menor tempo de produção para superar as expectativas dos clientes (GHALAYINI; NOBLE; CROWE, 1997).

A literatura contábil tem discutido a crescente ênfase no uso de uma combinação de indicadores de desempenho financeiros com os não-financeiros (ITTNER et al., 1997; SAID et al., 2003; STRIVES, et al., 1998). Essas discussões são justificadas pela necessidade das empresas implementarem estratégias de gestão de longo prazo. Para medilas é preciso fazer uso de indicadores não financeiros capazes de mensurar os ativos intangíveis que não podem ser medidos apenas por indicadores financeiros.

Levantamento realizado na literatura contábil evidencia a carência de pesquisas a respeito da combinação de indicadores de desempenho financeiros e não financeiros utilizados em hospitais.

O Rio Grande do Norte, desde o ano 2000 até 2004 é o estado do Nordeste que possui maior despesa com saúde por habitante (BRASIL, 2007). A rede hospitalar do estado do referido Estado é constituída por 176 unidades hospitalares, desses 100 são públicos, 73 privados e 3 universitários (BRASIL, 2003).

Conhecer os indicadores de desempenho dos hospitais é importante para que se possa compará-los com outras instituições com as mesmas características, proporcionar um melhor aproveitamento dos recursos, monitorar os avanços em termos de resultados ou de impactos, proporcionar maior responsabilização dos gestores e colaboradores e reduzir a atual assimetria de informação, subsidiando, assim a tomada de decisão pelos diversos agentes.

Diante desse contexto, essa pesquisa tem como objetivo geral investigar as principais características da medição de desempenho dos hospitais localizados no estado Rio Grande do Norte. Para isso, são definidos os seguintes objetivos específicos: Identificar os indicadores de desempenho, à luz da teoria, utilizados pelos hospitais; e Verificar se os gestores dos hospitais estão utilizando em seu processo de gestão os indicadores de desempenho, de acordo com o estado da arte desta área do conhecimento. 


\section{ORGANIZAÇÕES HOSPITALARES}

Os hospitais, assim como outras organizações prestadoras de serviços, possuem características como: pouca tolerância a erros; não podem funcionar efetivamente sem uma coordenação interna, motivação, autodisciplina e ajustes informais e voluntários de seus membros; organizações formais e hierarquizadas; além de serviços de atenção e tratamento personalizado aos pacientes individuais. Apesar das semelhanças, aqueles, na maioria das vezes, são procurados por seus clientes em circunstâncias alheias ao seu desejo, sem total conhecimento da intervenção, exame ou quais medicamentos irá consumir, por se encontrarem em condições que os impossibilitem negociar valores e prescrições.

Devido à quantidade e diversidade dessa instituição, o Sistema Único de Saúde (BRASIL, 2002) adota a seguinte classificação: Hospital de Porte I; de Porte II; de Porte III; e de Porte IV. Essa classificação agrupa os hospitais com características semelhantes, facilitando a adoção de políticas e planejamento, e reflete fielmente a realidade de cada uma das instituições hospitalares.

Colauto e Beuren (2003) ressaltam que o sucesso da referida administração reside em um melhor aproveitamento racional dos recursos estruturais, humanos e de clientes, requerendo para tal intento, que cada estratégia operacional seja direcionada no sentido da consecução dos objetivos institucionais.

Conforme Silva et al. (2006), gerir um hospital é extremamente difícil, pois quando a sua administração é realizada por profissionais sem devidas especializações, ocasiona conflitos no processo decisório orçamentário e financeiro, por existir bloqueios nos sistemas e canais de informação fundamentais para boa gestão hospitalar.

Os conflitos enfrentados pelo gestor sem conhecimento teórico e prático são ocasionados pela autonomia dada aos médicos e enfermeiros que, na fragilidade daqueles, utiliza-se de sua formação para interferir na esfera administrativa, ocasionando desentendimentos, os quais podem prejudicar o funcionamento institucional. 


\section{PROCESSO DE GESTÃO}

O processo de gestão é um eficaz procedimento de controle, que tem por objetivo assegurar a eficácia empresarial (CATELLI et al., 2001). Para que ele se concretize são necessárias as seguintes fases: planejamento, execução e controle.

a) Planejamento

O planejamento é utilizado para prever surpresas desagradáveis e prevenir contra os danos que possam prejudicar o resultado esperado. Para Martins (2001), é a tarefa básica do processo administrativo que prepara o hospital para seus objetivos, consistindo na elaboração de orçamentos expressos em dados físicos e financeiros, tais como: volume de procedimentos médicos, materiais e medicamentos (expressos em valores monetários de custos); despesas e receitas; além do estabelecimento do objetivo financeiro principal da administração do hospital, que é o de manter o equilíbrio entre custos, despesas e receitas para que sobreviva no sistema de economia de mercado.

Nesse processo, se determinam os objetivos e metas organizacionais, além da forma de como realizá-los. Dissertando sobre as estratégias e metas de longo e curto prazo, Kaplan e Norton (1997) afirmam que ao compartilhá-los com os funcionários, as empresas promovem a participação e o comprometimento destes no alcance dos objetivos traçados pela direção.

O planejamento divide-se em três níveis: estratégico, tático e operacional. Para alcançá-los, dentro da máxima eficiência, é indispensável que a empresa obtenha consonância entre os recursos físicos e financeiros, para se ter uma definição precisa dos recursos necessários, compatíveis com os prazos e custos.

Uma das etapas do planejamento é a elaboração do orçamento, com objetivo de orientar os gestores quanto aos objetivos e metas a serem executados, na maioria das vezes, em um período de doze meses. Os planos da administração em termos específicos e quantitativos são formalmente expressos em orçamentos, elaborados anualmente para apoiar a coordenação e implementação daqueles (PEREZ JÚNIOR; PESTANA; FRANCO, 1995). 
A avaliação de desempenho é realizada pela análise das variações orçamentárias, obtidas através de comparações entre os resultados reais e os orçados, que serão analisadas para determinação das causas das diferenças existentes (REIS; NEVES JÚNIOR; MORGAN, 2005).

Os hospitais públicos elaboram o orçamento, como um ato preventivo e autorizativo das receitas e despesas que devem executar durante um exercício. $\mathrm{O}$ orçamento anual da seguridade social (saúde, assistência e previdência social), está sujeito à aprovação por meio de lei.

b) Execução e Controle

A execução, conforme Mosimann e Fisch (1999), é a fase onde as coisas acontecem, devendo estar em conformidade com o planejado. Nessa etapa são armazenados dados referentes ao desempenho realizado para elaboração de relatórios, os quais possibilitarão comparação com planos e padrões na fase de controle. Já para Catelli et al. (2001), é a fase onde os recursos são consumidos e os produtos elaborados.

Martins (2001), corroborando com os já citados autores, complementa: após estabelecidos os objetivos e preparados os respectivos planos de trabalho inicia-se essa tarefa. Primeiramente, implantam-se as unidades organizacionais produtivas e auxiliares, em que o hospital desenvolverá suas atividades, com ênfase no planejamento e controle da produção médica, nas vendas dos serviços e na delegação de autoridade e responsabilidade. Essas unidades são descritas no organograma do hospital, instrumento essencial para concretização das responsabilidades e análises dos custos e despesas hospitalares.

Após esta fase ou paralelamente a ela, ocorre aquela denominada de controle, que visa assegurar que as atividades se realizem conforme planejado, provendo correções para problemas existentes na fase de execução e planejamento. Contribuindo, assim, para a manutenção e melhoria da posição competitiva e a consecução das estratégias, planos, programas e operações.

Os responsáveis pela condução do processo decisório devem estar atentos a esses três ciclos do processo de gestão: planejamento, execução e controle. O processo de gestão determina 
o sucesso da organização. A fase que deve deter maior tempo do gestor é o planejamento, seguida do controle.

\section{MEDIÇÃO E INDICADORES DE DESEMPENHO}

A eficiência do hospital requer o monitoramento sistemático das operações, o qual permite acompanhar a evolução ao longo do tempo em busca de suas metas. Através da medição de desempenho é possível realizar a monitoração, uma vez que os indicadores fornecem séries temporais de dados.

A medição de desempenho das instituições é necessária à gestão empresarial, sendo compreendida como a técnica usada para quantificar a eficiência e a eficácia das atividades de negócio (NEELY; GREGORY; PLATTS, 1995; O’MARA et al.,1998).

A medição de desempenho serve de base para a organização avaliar como está progredindo no alcance dos objetivos predeterminados, além de identificar as áreas fortes e fracas na empresa, indicando assim os setores nos quais o desempenho precisa ser melhorado (PURBEY; MUKHERJEE; BHAR, 2007).

As organizações, as quais não implantam a contínua medição de desempenho e sua realimentação, tendem a experimentar redução nas melhorias esperadas, tendo em vista a necessidade de informações oportunas e fidedignas sobre fatos para que o administrador possa tomar decisões. Apesar dessa verdade inquestionável, há uma tendência em confiar na intuição e opiniões sem qualquer apoio de fatos reais (PURBEY; MUKHERJEE; BHAR, 2007).

A medição de desempenho proporciona aos gestores hospitalares evidências sobre práticas existentes, valores, convicções e suposições, os habilitando para o desenvolvimento dos meios sistemáticos de identificar oscilações no planejamento e prevê melhoras no desempenho futuro. 
Diversos autores (NEELY; GREGORY; PLATTS, 1995; ITTNER et al., 1997; O’MARA, et al.,1998; SAID et al., 2003), ao longo do tempo, foram observando em seus estudos as limitações das medidas financeiras como ferramentas para a tomada de decisão estratégica diante do novo cenário, dada a incapacidade de medir adequadamente o desempenho, por deixar de fora indicadores como habilidades e treinamentos dos colaboradores, satisfação dos clientes e qualidade do produto ou serviço prestado, além dos resultados financeiros, às vezes, estarem defasados para serem úteis. Por isso, afirmam que deve existir um balanceamento no uso de indicadores financeiros e não financeiros de forma a suportarem a estratégia global da empresa previamente estabelecida.

Saraceno e Levav (1992 apud JUNG; JACQUES, 2006) descrevem: os indicadores de desempenho são variáveis que medem quantitativamente as variações no comportamento dos critérios de qualidade anteriormente estabelecidos. Por descrever uma realidade, deve ter as características de uma medida válida em termos estatísticos, como exatidão, confiabilidade, simplicidade, pertinência, validade e sensibilidade.

Para serem úteis à gestão, os indicadores devem estar normalizados e sua série temporal carece da fixação da norma ou forma de medida, para permitir a comparabilidade, com a visualização das tendências no tempo e nos dados da própria organização, da concorrência e com os referenciais de excelência. A análise desses indicadores proporciona conclusões relevantes para a tomada de decisões nos vários níveis da organização.

A escolha de quais indicadores são mais adequados é feita a partir da identificação das necessidades estratégicas, no momento apropriado do ciclo de vida em que se encontra a empresa (MIYABARA, FRANKLIN, GARDESANI 2004). Para Kaplan e Norton (1997), o ciclo de vida pode ser dividido em três fases: crescimento - onde os investimentos são elevados, sustentação - período no qual se espera o retorno do capital investido - e colheita, fase da maximização do fluxo de capital.

Os indicadores financeiros demonstram se a implantação e a execução da estratégia estão contribuindo para a melhoria do resultado. Para Moers (2000), esses indicadores contemplam três pontos fundamentais: liquidez, rentabilidade e endividamento. 
Os dados utilizados para sua análise são extraídos do balanço patrimonial e demonstração do resultado do exercício da empresa.

Segundo Galas e Ponte (2004), nas organizações governamentais e nas sem fins lucrativos, cujo o objetivo é o cumprimento de suas missões, esses indicadores são pouco utilizados, uma vez que essas entidades não tem como foco a situação financeira e sim a satisfação da sociedade.

Segundo Ghalayini e Noble (1996), os indicadores financeiros tentam quantificar o desempenho e as melhorias em termos financeiros. No entanto, parte das melhorias dificilmente é quantificada em termos monetários, como redução de tempo, a satisfação do cliente e a qualidade do produto. Além disso, os relatórios financeiros são incompreensíveis para os operadores, levando-os a frustração e insatisfação, fazendo com que esses profissionais ignorem esses relatórios.

Ao serem utilizados juntamente com os indicadores não financeiros, permitem que os administradores entendam as relações entre os diversos objetivos estratégicos, abrangendo as dimensões do cliente, do intangível, do aprendizado e crescimento, variáveis necessárias para as tomadas de decisões e para vantagem competitiva.

Atualmente, as empresas passaram a acreditar que os resultados financeiros positivos decorrem da bem-sucedida implantação dos fatores-críticos de sucesso medidos através de indicadores não financeiros, resultando assim em resultados financeiros superiores (SHANK; GOVINDARAJAN, 1997). Essa afirmação enfatiza a necessidade da implantação de ambos, haja vista apenas indicadores financeiros não suprirem as necessidades organizacionais.

Quanto à periodicidade, os indicadores não financeiros podem ser elaborados diariamente, proporcionando aos gerentes, supervisores e funcionários informações tempestivas para tomada de decisão (GHALAYINI; NOBLE, 1996).

Por sua vez, os financeiros não são obtidos com essa agilidade, tendo em vista a necessidade, inicialmente, da elaboração do balanço patrimonial e demonstração do resultado do exercício, que normalmente demoram um mês para serem finalizados. Conforme Ghalayini e Noble (1996), esses indicadores refletem decisões passadas, por isso, 
os resultados dos relatórios financeiros são considerados pelos operadores, supervisores, gerentes operacionais como resultado demasiadamente velho para ser útil para a avaliação do desempenho operacional.

Pesquisadores e profissionais têm sido unânimes em relatar a complexidade envolvida na tarefa de selecionar os indicadores de desempenho institucional mais adequados para apoiar a gestão dos hospitais e a necessidade de serem estudadas as características e os fatores determinantes do uso destes instrumentos pelos administradores (ESCRIVÃO JÚNIOR, 2007)

Goldstein e Ward (2004) afirmam ser difícil avaliar o desempenho hospitalar devido ao desafio de encontrar indicador adequado para esta organização. Em seu estudo, na busca por indicadores que reflitam os efeitos das operações, relatam que a taxa de ocupação e a proporção média da capacidade de camas utilizadas são medidas específicas para essas instituições, cujo uso é freqüente nas pesquisas sobre saúde.

No Brasil tem sido sugerida a avaliação dos profissionais e dos hospitais com base nos indicadores mais facilmente obteníveis. Dentre os indicadores não financeiros utilizados pelos hospitais tem-se: satisfação do cliente, qualidade dos serviços prestados, cirurgias por sala, proporções de cirurgias suspensas, taxa de mortalidade, percentual de cesáreas (AZEVEDO, 1991).

Além da taxa de mortalidade e do percentual de cesáreas citados acima, Jung e Jacques (2006) dissertam que os indicadores mais conhecidos para avaliar a qualidade da assistência à saúde prestada em hospitais são, principalmente, tempo de permanência, taxa de readmissão imediata, taxa de infecção hospitalar e complicações cirúrgicas. Marinho (2001) utiliza três indicadores em sua pesquisa: a taxa de ocupação de leitos, o tempo médio de permanência e a taxa de rotatividade dos leitos.

Bittar (1996) em sua pesquisa optou pelo uso da taxa de ocupação, taxa de infecção hospitalar e média de permanência. Já Zucchi, Bittar e Haddad (1998), média de permanência, índice de renovação ou giro de rotatividade (relação entre o número de pacientes que saíram do hospital durante determinado período e o número de leitos postos à disposição, no mesmo período) e relação funcionários por leito (número total de 
funcionários constantes da folha de pagamento dos hospitais em relação à soma do número de leitos existentes).

\section{BENCHMARKING}

$\mathrm{Na}$ atual conjuntura, tem se intensificado a utilização de indicadores e informações para comparar as organizações de saúde, buscando levá-las a níveis de superioridade e vantagem competitiva, por meio de referências de processos, práticas ou medidas de desempenho (GRIFFITH; KING, 2000 apud ESCRIVÃO JÚNIOR, 2007)

Para Kay (2007), o benchmarking é um processo de comparação das características de desempenho, com objetivo de permitir que cada participante melhore seu desempenho no mercado local, através de inovações nos processos ou nos produtos.

Esse contínuo processo é realizado através da identificação, compreensão e adaptação das práticas das organizações de referência do setor, entre departamentos de uma mesma empresa ou entre instituições do mesmo grupo, conduzindo então a um desempenho superior, uma melhor prestação do serviço aos clientes e utilização mais eficiente dos recursos.

Dentre as formas de obtenção das informações para se efetuar o benchmarking destacam-se: visitas a empresas líderes de alguma atividade; pesquisa em publicações especializadas; propagandas; entrevistas e contatos com clientes, profissionais e consultores; informativos técnicos e comerciais; teste de laboratório; estudos de comparação; parceiras com compartilhamento de informações (TAKASHINA; FLORES, 2005).

Como pôde ser observado, a ferramenta benchmarking pode ser utilizada pelos hospitais para demonstrar sua eficácia, bem como identificar as formas de melhorias. Através dessa avaliação, subsidiada pela percepção de usuários, existe a possibilidade de seus gerentes repensarem sobre o atendimento prestado e, assim, satisfazer as expectativas daqueles. 


\section{METODOLOGIA}

Esse estudo é do tipo descritivo, por ter como objetivo expor e estudar as características de uma determinada população, além de estabelecer correlações entre variáveis.

Para atingir os objetivos propostos e, conseqüentemente, obter resposta para o problema, realiza-se, inicialmente, uma pesquisa bibliográfica. Depois de constituído o arcabouço teórico, o passo seguinte, foi à realização da pesquisa empírica por meio do estudo de campo. A população objeto de estudo é composta por 176 instituições (BRASIL, 2003).

Nessa pesquisa optou-se pela seleção de uma amostra, devido à limitação orçamentária, disposição da população e à necessidade de agilizar a coleta de dados, porém mantendo a preocupação com sua representatividade. A técnica utilizada para seleção da amostra é não probabilística intencional.

Dessa forma, foram selecionados os municípios com mais de 50.000 habitantes, conforme as classes de tamanho da população dos municípios do IBGE (2007), juntamente com a cidade de Pau dos Ferros, por ser a única abaixo dessa faixa que possui 3 hospitais. Esta seleção resultou numa amostra representativa de hospitais que atendem mais de $51 \%$ da população de habitantes do estado Rio Grande do Norte.

Os 9 municípios (Natal, Mossoró, Parnamirim, São Gonçalo do Amarante, CearáMirim, Macaíba, Caicó, Açu, Currais Novos, São José de Mipibú e Pau dos Ferros) selecionados possuem juntos 52 hospitais, segundo Cadastro Nacional dos Estabelecimentos de Saúde (2007), destes, 3 participaram do pré-teste e 46 responderam à versão final do formulário, sendo assim, esse último total representa o tamanho da amostra utilizada.

A coleta de dados nessas entidades é realizada por meio de formulário objetivo, constituído por questões dispostas em escalas de classificação: de categoria simples, de múltipla escolha e escala Likert (COOPER; SCHINDLER, 2003). 
Para orientar a direção do estudo e fornece uma estrutura para organizar os resultados, estudo testa as seguintes hipóteses, através do Teste Exato de Fisher, para alcançar o objetivo geral:

$\mathbf{H}_{1}$ : Existe relação entre a natureza jurídica das organizações hospitalares e a finalidade do orçamento.

$\mathbf{H}_{\mathbf{2}}$ : Existe associação entre a natureza jurídica das organizações e a quantidade de indicadores financeiros utilizados.

Após tabulação dos dados coletados, foi realizada a análise descritiva baseadas em medidas de posição, de tendência central, comparação de freqüência e medidas de dispersão, por meio de tabelas e gráficos. Algumas variáveis foram cruzadas para verificar se existe associação entre elas e assim verificar a aceitação ou não das hipóteses descritas no tópico anterior. Para os cruzamentos foi utilizado o Software Statistical Package for the Social Science (SPSS), versão 13.0 para Windows.

\section{ANÁLISE DE DADOS}

Este tópico apresenta uma descrição dos dados obtidos através do formulário de pesquisa durante a coleta de dados.

Quanto à função desempenhada pelo respondente, através dos resultados obtidos com aplicação do formulário de pesquisa, observa-se que há uma predominância de Gerente/Administrador, 60,87\%, seguido por diretores, $28,26 \%$. O resultado apresentado pressupõe a confiabilidade dos dados, haja vista serem respondidos por profissionais detentores dos conhecimentos necessários para responder o referido instrumento.

O tempo médio de experiência dos respondentes é de 8,67 anos, esse tempo pressupõe que esses profissionais possuem conhecimento do hospital suficiente para fornecer respostas fidedignas. 
Tabela 1. Grau de instrução do gestor geral

\begin{tabular}{lll}
\hline \hline Grau de instrução & Freqüência & \% \\
\hline Pós-graduação Completa & 23 & 50,00 \\
Pós-graduação Incompleta & 2 & 4,35 \\
Ensino Superior Completo & 19 & 41,30 \\
Ensino Médio Completo & 2 & 4,35 \\
\hline Total & $\mathbf{4 6}$ & $\mathbf{1 0 0 , 0 0}$ \\
\hline \hline
\end{tabular}

Fonte: pesquisa de campo

Em relação ao grau de instrução do gestor geral da amostra pesquisada, observa-se a boa qualificação desse profissional, a qual pode refletir em uma melhor gestão hospitalar. Dos gestores, 50\% possuem pós-graduação completa, seguido de $41,30 \%$ com ensino superior completo e apenas $4,35 \%$ com ensino médio completo, esse último resultado é proveniente de uma única cidade do interior onde os pesquisadores percebem por meio de comentários do respondente que os conhecimentos políticos são determinantes para ocupação de tal função.

Tabela 2. Área(s) de conhecimento do gestor geral

\begin{tabular}{lll}
\hline \hline Área(s) de conhecimento & Freqüência & \% \\
\hline Medicina & 9 & 19,57 \\
Medicina/Administração & 9 & 19,57 \\
Medicina/Administração/Economia & 2 & 4,35 \\
Administração & 8 & 17,39 \\
Administração/Ciências contábeis/Outras & 2 & 4,35 \\
Administração/Economia & 1 & 2,17 \\
Administração/Ciências contábeis & 1 & 2,17 \\
Administração/Outras & 4 & 8,70 \\
Economia & 3 & 6,52 \\
Outras & 7 & 15,22 \\
\hline Total & $\mathbf{4 6}$ & $\mathbf{1 0 0 , 0 0}$ \\
\hline \hline
\end{tabular}

Fonte: pesquisa de campo

Do total da amostra pesquisada, 20 gestores gerais têm conhecimento na área de medicina, 27 em administração, 6 em economia, 3 em ciências contábeis e 13 em outras áreas, como enfermagem, serviço social, biologia, odontologia, direito e nenhuma. Os gestores que não possuem nenhuma área de conhecimento são dos referidos hospitais comentados acima, onde apesar de não terem conhecimento para a função, as ocupam por influência política. $O$ resultado da tabela 2 confirma o exposto no referencial teórico: por 
serem organizações complexas, os hospitais necessitam de profissionais qualificados para a sua administração.

Gráfico 1. Assessoria profissional

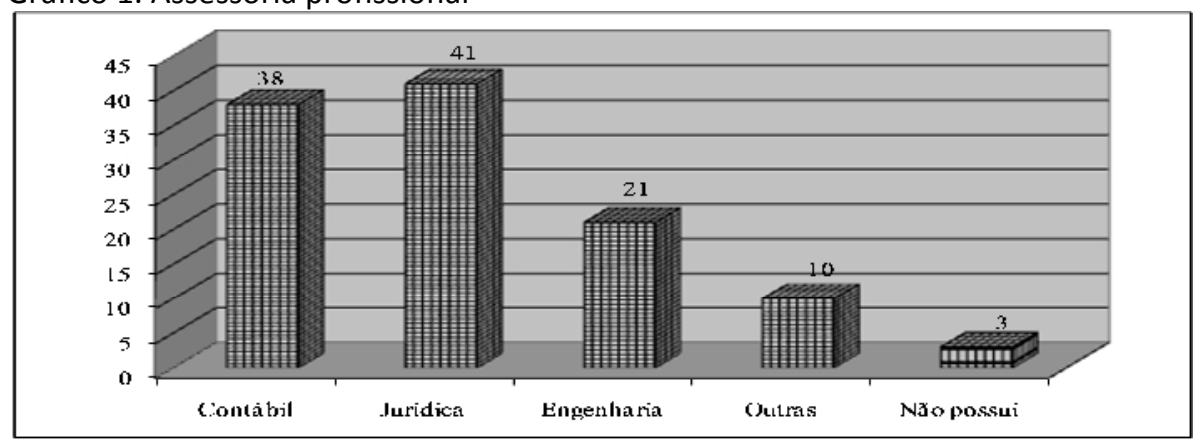

Fonte: pesquisa de campo

De acordo com o gráfico 1, dos 46 hospitais pesquisados, 41 utilizam assessoria jurídica, 38 contábil, 21 engenharia e 10 outras assessorias, como administrativa, serviço social, marketing, vigilância sanitária, financeira, médica e informática.

Tabela 3. Natureza jurídica da entidade

\begin{tabular}{lll}
\hline \hline Natureza Jurídica & Freqüência & $\%$ \\
\hline Pública & 23 & 50,00 \\
Privada sem fins lucrativos & 8 & 17,39 \\
Privada com fins lucrativos & 15 & 32,61 \\
\hline Total & $\mathbf{4 6}$ & $\mathbf{1 0 0 , 0 0}$ \\
\hline \hline Fonte: pesquisa de campo &
\end{tabular}

De acordo com a tabela 3, nota-se que $50 \%$ das entidades são públicas, $32,61 \%$ são de natureza privada com fins lucrativos e $17,39 \%$ de natureza privada sem fins lucrativos.

Conforme o porte dos hospitais pesquisados, observa-se que mais de $70 \%$ estão entre os Portes II e III, 39,13\% são de Porte III e 36,96\% de Porte II. Dos demais 17,39\% são de Porte I e apenas 6,52\% de Porte IV. 


\section{CARACTERÍSTICAS DA MEDIÇÃO DE DESEMPENHO ORGANIZACIONAL: UM ESTUDO DESCRITIVO NOS HOSPITAIS DO ESTADO DO RIO GRANDE DO NORTE \\ Edzana Roberta F. da C. V. Lucena, Aneide Oliveira Araújo - César Augusto Tibúrcio da Silva}

Tabela 4. Níveis de planejamento realizado pela organização

\begin{tabular}{lll}
\hline \hline Níveis de planejamento da organização & Freqüência & \% \\
\hline Estratégico & 4 & 8,70 \\
Operacional & 16 & 34,78 \\
Tático & 9 & 19,57 \\
Estratégico/Operacional & 7 & 15,22 \\
Estratégico/Tático/Operacional & 6 & 13,04 \\
Tático/Operacional & 4 & $\mathbf{8 , 7 0}$ \\
\hline Total & $\mathbf{4 6}$ & $\mathbf{1 0 0 , 0 0}$ \\
\hline \hline
\end{tabular}

Fonte: pesquisa de campo

Quanto aos níveis de planejamento, das 46 empresas pesquisadas, 17 utilizam o planejamento estratégico. Dessas, 4 fazem uso apenas dele (8,70\% da amostra), 7 (15,22\% da amostra) o usam em conjunto com o planejamento operacional e 6 (13,04\% da amostra) empregam os três níveis. Os hospitais que utilizam apenas o planejamento estratégico, a literatura afirma ser insuficiente, devido à necessidade de estabelecer objetivos de curto prazo para o cumprimento dos de longo. Sendo assim, a implantação apenas deste planejamento dificulta o cumprimento da missão.

Tabela 5. Divulgação dos planos, estratégias e metas versus periodicidade

\begin{tabular}{|c|c|c|c|c|c|}
\hline \multirow{2}{*}{ Periodicidade } & \multicolumn{5}{|c|}{ Entidade divulga seus planos, estratégias e metas, entre: } \\
\hline & $\begin{array}{ll}\begin{array}{l}\text { Proprietários } \\
\text { gerentes }\end{array} \\
\end{array}$ & $\begin{array}{l}\text { Chefias/ } \\
\text { Mantenedores }\end{array}$ & Todos & Não divulga & Total \\
\hline \multirow{2}{*}{ Semanalmente } & 1 & 1 & 2 & & 4 \\
\hline & $2,17 \%$ & $2,17 \%$ & $4,35 \%$ & & $8,70 \%$ \\
\hline \multirow{2}{*}{ Mensalmente } & 2 & 7 & 10 & & 19 \\
\hline & $4,35 \%$ & $15,22 \%$ & $21,74 \%$ & & $41,30 \%$ \\
\hline \multirow{2}{*}{ Bimestralmente } & 1 & 1 & 0 & & 2 \\
\hline & $2,17 \%$ & $2,17 \%$ & $0,00 \%$ & & $4,35 \%$ \\
\hline \multirow{2}{*}{ Trimestralmente } & 2 & 2 & 3 & & 7 \\
\hline & $4,35 \%$ & $4,35 \%$ & $6,52 \%$ & & $15,22 \%$ \\
\hline \multirow{2}{*}{ Outros } & 3 & 3 & 7 & & 13 \\
\hline & $6,52 \%$ & $6,52 \%$ & $15,22 \%$ & & $28,26 \%$ \\
\hline \multirow{2}{*}{ Nunca } & & & & 1 & 1 \\
\hline & & & & $2,17 \%$ & $2,17 \%$ \\
\hline \multirow{2}{*}{ Total } & 9 & 14 & 22 & 1 & 46 \\
\hline & $19,57 \%$ & $30,43 \%$ & $47,83 \%$ & $2,17 \%$ & $100 \%$ \\
\hline
\end{tabular}

Fonte: pesquisa de campo

Quanto aos resultados da tabela 5, observa-se: apenas 2,17\% não efetuam divulgações, $19,57 \%$ das empresas pesquisadas fazem a divulgação apenas para proprietários e gerentes, $30,43 \%$ entre chefias ou mantenedores e $47,83 \%$ divulga para 
todos da instituição. Esse último resultado confirma a recomendações da literatura pesquisada, a qual relata que os planos, estratégias e metas devem ser divulgados para todos os envolvidos da organização, contribuindo para o alcance dos objetivos e, assim, a maximização do desempenho.

Em relação à periodicidade, visualiza-se que em 41,30\%, maior concentração de respondente, a divulgação dos planos, estratégias e metas ocorre mensalmente, sendo constituído esse total em grande parte por instituições onde todos participam do processo de divulgação. Seguido por outros períodos, $28,26 \%$, compostos por quadrimestre, semestre e ano.

A tabela abaixo faz um cruzamento das entidades que elaboram o orçamento com a finalidade desses, revelando: das empresas pesquisadas 63,04\% elaboram o orçamento, enquanto que as demais não o fazem. Esse elevado percentual dos hospitais que o elaboram justifica-se no tópico 3 desse artigo, onde esse é explicitado como uma ferramenta da fase de planejamento e controle capaz de proporcionar aos gestores o cumprimento dos objetivos e metas propostas.

Tabela 6. Elaboração do orçamento versus sua finalidade

\begin{tabular}{|c|c|c|c|}
\hline \multirow{2}{*}{ Finalidade do orçamento } & \multicolumn{3}{|c|}{ Elabora orçamento } \\
\hline & Sim & Não & Total \\
\hline \multirow{2}{*}{ Exigência da Lei 4.320/64 - Pleitear recursos } & 6 & 10 & 16 \\
\hline & $13,04 \%$ & $21,74 \%$ & $34,78 \%$ \\
\hline \multirow{2}{*}{ Comparar planejado com executado } & 9 & & 9 \\
\hline & $19,57 \%$ & & $19,57 \%$ \\
\hline \multirow{2}{*}{$\begin{array}{l}\text { Exigência da Lei - Pleitear recursos e Comparar planejado com } \\
\text { executado }\end{array}$} & 14 & & 14 \\
\hline & $30,43 \%$ & & $30,43 \%$ \\
\hline \multirow{2}{*}{ Não elabora orçamento } & & 7 & 7 \\
\hline & & $15,22 \%$ & $15,22 \%$ \\
\hline \multirow{2}{*}{ Total } & 29 & 17 & 46 \\
\hline & $63,04 \%$ & $36,96 \%$ & $100,00 \%$ \\
\hline
\end{tabular}

Fonte: pesquisa de campo

Apesar da literatura afirmar que através das comparações entre o orçado e o realizado as organizações podem avaliar seu desempenho, 13,04\% das instituições o faz apenas para pleitear recursos ou por exigência da lei 4.320/64. Talvez esse resultado se deva ao fato de, nos hospitais públicos, esse instrumento ser elaborado como um ato preventivo 
e autorizativo das receitas e despesas a serem executadas no exercício, autorizado por lei. Ressalta-se ainda, dos hospitais que responderam não elaborar o orçamento, em 10 deles, por exigência legal, o mesmo é feito pela Secretaria de Saúde da esfera de governo ao qual pertence, isso porque a instituição não possui independência financeira.

Tabela 7. Bases para tomadas de decisões

\begin{tabular}{lll}
\hline \hline Bases & Freqüência & \% \\
\hline Intuição do gestor & 9 & 19,57 \\
Relatórios e indicadores & 29 & 63,04 \\
Intuição do gestor/Relatórios e indicadores & 8 & 17,39 \\
\hline Total & $\mathbf{4 6}$ & $\mathbf{1 0 0 , 0 0}$ \\
\hline \hline
\end{tabular}

Fonte: pesquisa de campo

Os dados da tabela 7 evidenciam que a maioria absoluta dos respondentes, 63,04\%, afirmaram usar relatórios e indicadores para a tomada de decisões e 17,39\% informaram usar tanto relatórios indicadores quanto a intuição do gestor. As referências consultadas relatam que no mundo dos negócios a tomada de decisão baseada em intuição possui grandes chances de dar errada, por isso, deve se basear em análises e estudos junto aos diversos setores da entidade.

Na amostra pesquisada, conforme demonstração do gráfico abaixo, 52,17\% dos hospitais utiliza tanto relatórios financeiros quanto não financeiros, $28,26 \%$ usam somente relatórios não financeiros e 13,04\% apenas financeiros. Apesar da complexidade encontrada nessas instituições, 6,52\% não avaliam seus resultados.

Gráfico 2. Relatórios utilizados para análise dos resultados

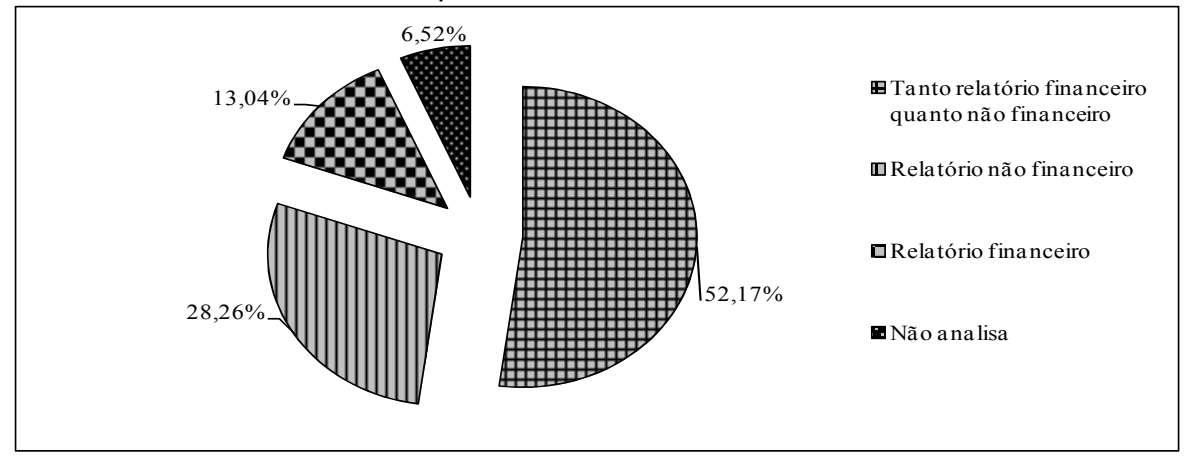

Fonte: pesquisa de campo 
Edzana Roberta F. da C. V. Lucena, Aneide Oliveira Araújo - César Augusto Tibúrcio da Silva

O fato da maioria dos hospitais fazerem uso juntamente de relatórios financeiros e não financeiros, de acordo com a literatura pesquisada, justifica-se por nessas organizações existirem rápidas mudanças tecnológicas e inovações nas prestações de serviços. Assim, apenas os indicadores financeiros não são capazes de refletir seu atual desempenho, porém são necessários para orientar investimentos e decisões estratégicas.

Tabela 8. A organização avalia seu desempenho versus utilização dessa informação para a tomada de decisão

\begin{tabular}{l|l|l|l}
\hline \multirow{2}{*}{ Auxilia na tomada de decisão } & \multicolumn{3}{|l}{ Avalia o desempenho } \\
\cline { 2 - 4 } & Sim & Não & Total \\
\hline \multirow{2}{*}{$\operatorname{Sim}$} & 37 & & 37 \\
\cline { 2 - 4 } & $80,43 \%$ & & $80,43 \%$ \\
\hline \multirow{2}{*}{ Não } & & 9 & 9 \\
\hline \multirow{2}{*}{ Total } & & $19,57 \%$ & $19,57 \%$ \\
\hline \hline
\end{tabular}

Fonte: pesquisa de campo

A tabela 8 averigua se os hospitais avaliam seu desempenho e a referida avaliação auxilia na tomada de decisão. De posse dos dados, nota-se: $80,43 \%$ das instituições pesquisadas avaliam seu desempenho e, dentre esse total, todas afirmam serem auxiliadas no processo decisório por essa avaliação. O elevado percentual encontrado é respaldado no referencial teórico deste estudo, que apresenta a avaliação de desempenho como uma ferramenta capaz de mensurar resultados não facilmente medidos ou padronizados das instituições, onde se enquadram os hospitais. Não obstante as virtudes existentes na avaliação do desempenho há 19,57\% que desconhece os benefícios provenientes desta.

Tabela 9. Uso do benchmarking e as principais fontes de informação

\begin{tabular}{|c|c|c|c|}
\hline \multirow{2}{*}{ Fontes de informação } & \multicolumn{3}{|c|}{ Utiliza benchmarking } \\
\hline & Sim & Não & Total \\
\hline \multirow{2}{*}{ Não realiza comparação } & & 21 & 21 \\
\hline & & $45,65 \%$ & $45,65 \%$ \\
\hline \multirow{2}{*}{ Pesquisas realizadas em empresas com características similares } & 9 & & 9 \\
\hline & $36,00 \%$ & & $19,57 \%$ \\
\hline \multirow{2}{*}{ Periódicos ou sites especializados do setor } & 4 & & 4 \\
\hline & $16,00 \%$ & & $8,70 \%$ \\
\hline \multirow{2}{*}{ Informações de consultores } & 4 & & 4 \\
\hline & $16,00 \%$ & & $8,70 \%$ \\
\hline \multirow{2}{*}{$\begin{array}{l}\text { Periódicos ou sites especializados do setor e Informações de } \\
\text { consultores }\end{array}$} & 2 & & 2 \\
\hline & $8,00 \%$ & & $4,35 \%$ \\
\hline
\end{tabular}

R. eletr. estrat. neg., Florianópolis, v.4, n.2, p. 154-180, jun./dez. 2011 


\begin{tabular}{l|l|l|l}
\hline \hline & \multicolumn{3}{c}{ Continuação } \\
\hline \multirow{2}{*}{ Fontes de informação } & \multicolumn{2}{l}{ Utiliza benchmarking } \\
\cline { 2 - 4 } & Sim & Não & Total \\
\hline & & & \\
\hline Pesquisas realizadas em empresas similares e Periódicos ou sites & 4 & & 4 \\
\cline { 2 - 4 } especializados & $16,00 \%$ & & $8,70 \%$ \\
\hline \multirow{2}{*}{ Outros } & 2 & & 2 \\
\hline \multirow{2}{*}{ Total } & $8,00 \%$ & $4,35 \%$ \\
\hline \hline
\end{tabular}

Fonte: pesquisa de campo

Através da tabela acima, observa-se que $54,35 \%$ dos hospitais pesquisados reconhecem a importância de tal mecanismo, fazendo assim uso em sua atividade. Desse total, 4 entidades utilizam como fonte de informação os periódicos ou sites especializados do setor, 4 usam informações de consultores, 2 utilizam tanto esse quanto aquele meio de obtenção, 9 instituições adquirem as informações por meio de pesquisas realizadas em empresas com Os principais indicadores financeiros de liquidez são utilizados por menos da metade dos hospitais investigados para mensurar o desempenho. Apenas $15,22 \%$ da amostra usam indicadores de Liquidez Seca, 39,13\% utilizam à Liquidez Geral e 39,13\% fazem uso da Liquidez Corrente. Visualiza-se também que apesar da liquidez seca ser pouco utilizada, ela possui um maior grau de importância para o auxílio à tomada de decisão (média 4,29), seguido pela liquidez geral, 4,06\%. O baixo percentual de usuários desse índice pode ser ocasionado devido $67,39 \%$ da amostra ser constituída por hospitais públicos e privados sem fins lucrativos, empresas nas quais a situação financeira não é o principal objetivo.

Quanto os indicadores de rentabilidade, $73,91 \%$ da amostra não utilizam Margem Líquida, mesma porcentagem apresentada para os não usuários do Retorno sobre o investimento. Já a rentabilidade sobre o patrimônio líquido é útil em 23,91\% dos estabelecimentos.

Dos hospitais analisados, $80,43 \%$ das entidades pesquisadas não utilizam a proporção do capital de terceiros em relação ao passivo total, $78,26 \%$ não fazem uso do indicador relação de capital de terceiros/capital próprio. $O$ índice de endividamento mais usado pelos hospitais é imobilização de recursos permanentes, 36,96\%. 
$\mathrm{Na}$ literatura pesquisada observou-se a complexidade envolvida na seleção dos indicadores não financeiros, por não existir um consenso sobre os melhores para avaliar os hospitais. Então foram investigados no formulário de pesquisa os indicadores mais evidenciados pelos diversos autores consultados.

Dos indicadores elencados no questionário, o que detém maior percentual de utilização é a evolução do número de pacientes (91,30\%), seguido pelo tempo de permanência do paciente, taxa de ocupação e valor de custos (todos usados por $86,96 \%$ dos hospitais analisados). Ressalta-se que essa preferência pode ser devido aos referidos indicadores influenciarem nos custos da organização.

Entre os indicadores menos utilizados destacam-se percentual de rejeição $(21,74 \%)$, erros de medicação $(28,26 \%)$ e número de erros dos colaboradores $(30,43 \%)$. Esse último apesar de não ser muito usado, possui, dentre os demais, a maior média - 4,93\%, acompanhado pelo percentual de glosa - 4,81\%, complicações cirúrgicas - 4,76\% e número de reclamações dos pacientes $-4,74 \%$.

A Tabela 10 apresenta o resultado da verificação da relação da natureza jurídica dos hospitais investigados e a finalidade do orçamento. Acreditava-se no pressuposto de que as entidades públicas e privadas sem fins lucrativos utilizavam o orçamento por uma exigibilidade legal e para pleitear recurso, enquanto que nas privadas com fins lucrativos, a finalidade seria possibilitar comparações do planejado e executado.

Tabela 10. A relação entre a natureza jurídica das organizações hospitalares e a finalidade do orçamento

\begin{tabular}{|c|c|c|c|}
\hline \multirow[b]{2}{*}{ Natureza jurídica } & \multicolumn{3}{|l|}{ Finalidade do orçamento } \\
\hline & $\begin{array}{l}\text { Exigência legal e } \\
\text { Pleitear recursos }\end{array}$ & $\begin{array}{l}\text { Comparar planejado } \\
\text { com executado }\end{array}$ & Total \\
\hline Pública e Privada sem fins lucrativos & 26 & 14 & 40 \\
\hline Privada com fins lucrativos & 4 & 9 & 13 \\
\hline Total & 30 & 23 & 53 \\
\hline Teste Estatístico & \multicolumn{3}{|l|}{ Teste Exato de Fisher } \\
\hline P-valor & \multicolumn{3}{|l|}{0,05} \\
\hline
\end{tabular}

Fonte: pesquisa de campo 
Ao se testar estatisticamente as variáveis, foi constatada a existência relação significativa entre elas, uma vez que o $p$-valor é igual 0,05. Portanto, a finalidade do orçamento depende da natureza jurídica do hospital.

A tabela 11 busca explicar se a natureza jurídica dos hospitais possui relação com o número de indicadores usados por esses. Conforme literatura pesquisada, as instituições públicas e privadas sem fins lucrativos, não possuem como meta a situação financeira, mas sim, o cumprimento de seus objetivos sociais, sendo assim, pouco utilizam indicadores financeiros.

Tabela 11. A relação entre a natureza jurídica das organizações e a quantidade de indicadores financeiros utilizados

\begin{tabular}{l|l|l|l}
\hline \hline \multirow{2}{*}{ Natureza Jurídica dos hospitais } & \multicolumn{2}{l}{$\begin{array}{l}\text { Número de } \\
\text { utilizados }\end{array}$} & \multicolumn{2}{l}{ Indicadores } & Financeiros \\
\cline { 2 - 4 } & $<\mathbf{5}$ & $\mathbf{>} \mathbf{5}$ & Total \\
\hline Pública e Privada sem fins lucrativos & 29 & 2 & 31 \\
\hline Privada com fins lucrativos & 3 & 12 & 15 \\
\hline Total & $\mathbf{3 2}$ & $\mathbf{1 4}$ & $\mathbf{4 6}$ \\
\hline Teste Estatístico & \multicolumn{2}{l}{} \\
\hline P-valor & $\mathbf{0 , 0 0 0 0 0 0 8}$ \\
\hline \hline
\end{tabular}

Fonte: pesquisa de campo

Por meio do Teste Exato de Fisher, a mencionada associação foi confirmada estatisticamente ( $p$-valor=0,0000008), devendo-se, no entanto, rejeitar a hipótese nula. Em outras palavras, os hospitais privados com fins lucrativos fazem uso de um maior número de indicadores financeiros do que os públicos e privados sem fins lucrativos.

\section{CONSIDERAÇÕES FINAIS}

A medição de desempenho evidencia a eficiência e a eficácia das atividades organizacionais. Através da obtenção de dados, essa ferramenta possibilita entender o funcionamento da empresa, além de monitorar e avaliar suas ações, antecipando mudanças na direção estratégica. Percebe-se, portanto, que as instituições estudas necessitam de medidas de desempenho para seu processo de gestão. 
A presente pesquisa alcançou o objetivo geral que é investigar as principais características da medição de desempenho dos hospitais localizados no estado Rio Grande do Norte.

Quanto aos objetivos específicos, esses também foram alcançados no Referencial Teórico, onde, para sua elaboração, realiza-se uma pesquisa bibliográfica e, assim, investigase o estado da arte da medição de desempenho e os indicadores financeiros e nãofinanceiros utilizados pelos hospitais. Observa-se uma grande diversidade de indicadores existentes e uma falta de consenso sobre quais os melhores indicadores para se avaliar hospitais. Tal fato dificulta na escolha daqueles que retratam fidedignamente a realidade dessas instituições.

Diante de tais resultados, observa-se que os hospitais privados com fins lucrativos utilizam no seu processo decisório uma combinação de indicadores de desempenho financeiros e não-financeiros, conforme recomenda a literatura pesquisada. Porém, os públicos e privados sem fins lucrativos fazem uso, em sua maioria, apenas dos indicadores não-financeiros.

Por meio das considerações feitas, pode-se concluir que grande parte das instituições analisadas faz uso, em seu processo de gestão, das principais medidas de desempenho investigadas. Assim, os hospitais pesquisados possuem dados para avaliar como estão evoluindo no alcance dos objetivos predeterminados e identificar as áreas em que o desempenho precisa ser melhorado.

\section{CHARACTERISTICS OF MEASURING ORGANIZATIONAL PERFORMANCE: A STUDY IN DESCRIPTION IN RIO GRANDE DO NORTE'S HOSPITALS}

\footnotetext{
ABSTRACT

This research aims to investigate the main characteristics of the measurement performance of hospitals in Rio Grande do Norte. For this purpose, we performed a descriptive, conducted in 46 hospitals in the state, selected from a non-probabilistic in the cities of Natal, Mossoró, Parnamirim, São Gonçalo do Amarante, Ceará-Mirim, Macaíba, Caicó, Açu, Currais 
Novos, São José de Mipibú and Pau dos Ferros. To collect the data, we used an objective questionnaire, consisting of 32 questions, arranged in rating scales for single category, multiple choice and Likert scale. After tabulating the data, perform analysis was descriptive and non-parametric statistical tests, chi-square and Fisher exact test. The results show that most of the institutions analyzed are being managed by professionals with good skills and knowledge in areas such as administration, accounting, economics and medicine, have a mission, do some planning, budgeting, report on their plans, strategies and goals, using indicators and reports for decision making, evaluate and compare the performance of organizations with similar characteristics. The hypotheses tested had statistically significant relationship. Given these results, it can be concluded that most of the hospitals listed in the original sample, uses in its process management of key performance measures investigated, having data to assess how they are progressing in achieving the predetermined goals and identify areas to be improved.

Keywords: performance measurement. Financial and nonfinancial indicators. Hospitals.

\section{REFERÊNCIAS}

AZEVEDO, Antonio Carlos de. Avaliação de desempenho de serviços de saúde. Revista de Saúde Pública, São Paulo, v.25, n.1, p.64-71, fev. 1991. Disponível em:

<http://www.scielosp.org/pdf/rsp/v25n1/13.pdf>. Acesso em: 24 abr. 2007.

BRASIL. Ministério da Saúde. Sistema de Informações Hospitalares do SUS (SIH/SUS), 2003. Disponível em: <http://tabnet.datasus.gov.br/cgi/tabcgi.exe?sih/cnv/cxrn.def>. Acesso em: 20 maio 2007.

BRASIL. Ministério da Saúde. Secretaria de Ciência, Tecnologia e Insumos Estratégicos. Sistema de Informações sobre Orçamentos Públicos em Saúde. Fundo Nacional de

Saúde.IBGE. Despesas com Ações e Serviços Públicos de Saúde financiadas por recursos próprios, em R\$ mil correntes, por esfera de governo. Disponível em:

<http://siops.datasus.gov.br/despsaude.php?escacmp=1>. Acesso em: 20 maio 2007.

BRASIL. Portaria do Ministério da Saúde e Secretaria Nacional de Assistência à Saúde $\mathbf{n}$.

2.224, de 5 de dezembro de 2002. Disponível em: 
<http://dtr2001.saude.gov.br/sas/PORTARIAS/Port2002/Gm/GM-2224.htm>. Acesso em: 10 ago. 2007.

BITTAR, Olímpio J. Nogueira V. Produtividade em hospitais de acordo com alguns indicadores hospitalares. Revista de Saúde Pública, São Paulo, v.30, n.1, fev.1996. Disponível em: $<$ http://www.scielo.br/scielo.php?script=sci_arttext\&pid=S0034-

$89101996000100007 \&$ Ing=pt\&nrm=iso\&tlng=pt>. Acesso em: 17 maio 2007.

CATELLI, Armando; PEREIRA, Carlos Alberto; VASCONCELOS, Marco Tullio de Castro. Processo de Gestão e Sistemas de informações gerenciais. In.: CATELLI, Armando (Org.). Controladoria: uma abordagem da gestão econômica. 2. ed. São Paulo: Atlas, 2001.

COLAUTO, Romualdo Douglas; BEUREN, Ilse Maria. Proposta para Avaliação da Gestão do Conhecimento em Entidade Filantrópica: o Caso de uma Organização Hospitalar. Revista de Administração Contemporânea (RAC), v.7, n.4, out./dez. 2003, p. 163-185. Disponível em: <http://www.anpad.org.br/rac/vol_07/dwn/rac-v7-n4-rdc.pdf>. Acesso em: 15 dez. 2007.

COOPER, Donald R.; SCHINDLER, Pamela S. Métodos de pesquisa em Administração. Tradução: Luciana de Oliveira da Rocha. 7. ed. São Paulo: Bookman, 2003.

ESCRIVÃO JÚNIOR, Álvaro. Uso da informação na gestão de hospitais públicos. Ciência \& Saúde Coletiva, Rio de Janeiro, v.12, n.3, p.655-666, maio/jun., 2007. Disponível em: <http://www.scielo.br/pdf/csc/v12n3/15.pdf>. Acesso em: 15 dez. 2007.

GALAS, Eduardo Santos; PONTE, Vera Maria Rodrigues. O Equilíbrio dos Indicadores do Balanced Scorecard: um Estudo em Empresas Cearenses. In.: Encontro da ANPAD, 28, 2004. Anais... Curitiba: ANPAD, 2004.

GHALAYINI, Alaa M.; NOBLE, James S. The changing basis of performance measurement. International Journal of Operations \& Production Management, v.16, n. 8, p. 63-80, 1996. Disponível em: <http://www.emeraldinsight.com/10.1108/01443579610125787>. Acesso em: 27 abr. 2007.

GHALAYINI, Alaa M.; NOBLE, James S.; CROWE, Thomas J. An integrated dynamic performance measurement system for improving manufacturing competitiveness. International Journal of Production Economics, v.48. n. 3, p. 207-225, fev./1997. Disponível em: <http://www.sciencedirect.com/science/article/B6VF8-3T7HKY9-

1/2/bb976dc7286fa5fbe521e31301ef2bda>. Acesso em: 27 abr. 2007.

GOLDSTEIN, Susan Meyer; WARD, Peter T. Performance Effects of Physicians' Involvement in Hospital Strategic Decisions. Journal of Service Research, v.6, n.4, p. 361-372, 2004.

Disponível em: <http://jsr.sagepub.com/cgi/content/abstract/6/4/361\#BIBL>. Acesso em: 07 maio 2007. 
INSTITUTO BRASILEIRO DE GEOGRAFIA E ESTATÍSTICA. População residente, em $1 \stackrel{0}{\text { de }}$ abril de 2007, segundo os municípios. Disponível em:

<http://www.ibge.gov.br/home/estatistica/populacao/contagem2007/popmunic2007layout TCU14112007.xls>. Acesso em: 10 ago. 2007.

ITTNER, Christopher D.; LARCKER, David F.; RAJAN, Madhav V. The choice of performance measures in annual bonus contracts. The Accounting Review, v. 72, n.2, p. 231-255, abr.1997.

JUNG, Gladis; JACQUES, Édison. Análise do Desempenho Hospitalar: uma abordagem através do Balanced Scorecard e do pensamento sistêmico. In.: Encontro da ANPAD, 30, 2006. Anais... Salvador: ANPAD, 2006.

KAY, Jay F. L. Health Care Benchmarking. Medical Bulletin, v.12, n.2, fev./2007. Disponível em: <http://www.fmshk.org/database/articles/06mbdrflkay.pdf>. Acesso em: 16 fev. 2008

KAPLAN, Robert S.; NORTON, David P. A Estratégia em Ação: Balance Scorecard. Rio de Janeiro: Campus, 1997.

MARINHO, Alexandre. Hospitais universitários: indicadores de utilização e análise de eficiência. Rio de Janeiro: IPEA, 2001. Disponível em:

<http://www.ipea.gov.br/pub/td/td_2001/td_0833.pdf>. Acesso em: 15 dez. 2007. (Texto para discussão n. 833).

MARTINS, Domingos. Gestão financeira de hospitais. 2. ed. São Paulo: Atlas, 2001.

MIYABARA, Walter; FRANKLIN, Marcos Antônio; GARDESANI, Roberto. A cultura e comportamento em relação à informação e sua conexão com o desempenho competitivo: uma aplicação na indústria de autopeças para veículos. In.: Encontro da ANPAD, 28, 2004. Anais... Curitiba: ANPAD, 2004.

MOERS, Frank. Financial and non-financial performance measures and managerial shortterm orientation: the interactive effect of performance targets. MARC Working Paper, 2000. Disponível em:

<http://www.som.cranfield.ac.uk/som/research/centres/cbp/pma/FORUM\%20-\%20nonfianancial\%20pm.pdf>. Acesso em: 2 jan. 2008.

MOSIMANN, Clara Pellegrinello e FISCH, Silvio. Controladoria: seu papel na administração de empresas. 2. ed. São Paulo: Atlas, 1999.

NEELY, Andy; GREGORY, Mike; PLATTS, Ken. Performance measurement system design: A literature review and research agenda. International Journal of Operations \& Production Management. v.15. n. 4, p. 80-116, 1995. Disponível em: <http://www.emeraldinsight.com/10.1108/01443570510633639>. Acesso em: 27 abr. 2007. O'MARA, Charles E. et al. Performance measurement and strategic change. Managing Service Quality. v. 8, n. 3, p. 179-182, 1998. 
PEREZ JUNIOR, José Hernandez; PESTANA, Armando Oliveira; FRANCO, Sérgio Paulo Cintra. Controladoria de gestão: teoria e prática. São Paulo: Atlas, 1995.

PURBEY, Shankar; MUKHERJEE, Kampan; BHAR, Mukherjee. Performance measurement system for healthcare processes. International Journal of Productivity and Performance Management, v. 56, n. 3, p. 241-251, 2007. Disponível em: <www.emeraldinsight.com/17410401.htm>. Acesso em: 03 dez. 2007.

REIS, Solange Garcia; NEVES JÚNIOR, Idalberto José; MORGAN, Beatriz Fátima. Determinantes de metas para avaliação de desempenho de agências bancárias. Congresso USP Controladoria e Contabilidade, 5, 2005. Anais... São Paulo: USP, 2005. Disponível em: <http://www.congressoeac.locaweb.com.br/artigos52005/161.pdf>. Acesso em: 27 abr. 2007.

SAID, Amal A.; HASSABELNABY, Hassan R; WIER, Benson. An Empirical Investigation of the Performance Consequences of Nonfinancial Measure. Journal of Management Accounting Research; 2003; 15, ABI/INFORM Global, p. 193.

SHANK, John K.; GOVINDARAJAN, Vijay. Como reinventar e redefinir sua estratégia de custos para vencer em mercados crescentes e competitivos. In: A revolução dos custos. Tradução de Luiz Orlando Coutinho Lemos. 7. ed. Rio de Janeiro: Campus, 1997.

SILVA, Maria Daniella de O. Pereira et alli. Uma análise comparativa dos indicadores de desempenho de uma entidade de saúde pública de Caruaru - PE: um aplicativo estratégico do Balanced Scorecard. In.: Congresso USP de Iniciação Científica, 3, 2006. Anais... São Paulo: USP, 2006. Disponível em:

<http://www.congressoeac.locaweb.com.br/artigos32006/557.pdf>. Acesso em: 03 dez. 2007.

STRIVES, B. P.; COVIN, T. J; HALL, N.G.; SMALT, S. W. How nonfinancial performance measures are used: Survey of Fortune 500 and Canadian Post 300 executives. Management Accounting, n. 44, fev.1998.

TAKASHINA, N.T.; FLORES, M.C.X. Indicadores de qualidade e do desempenho: como estabelecer metas e medir resultados. Rio de Janeiro, Qualitymark, 2005.

ZUCCHI, Paola; BITTAR, Olímpio J. Nogueira V.; HADDAD, Nagib. Produtividade em hospitais de ensino no estado de São Paulo, Brasil. Revista Panamericana de Salud Públican, v.4, n.5, p.311-316, nov./1998, Washington. Disponível em:

<http://www.scielosp.org/pdf/rpsp/v4n5/4n5a4.pdf>. Acesso em: 27 maio 2007. 